\title{
The Experimental Investigation of the Optimization of the Flow State of a Ladder-Shaped Spillway in a Certain Reservoir
}

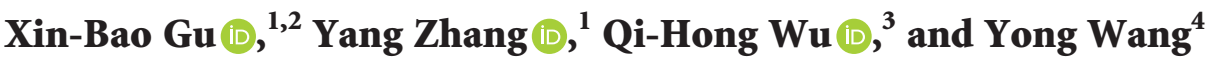 \\ ${ }^{1}$ School of Civil Engineering, Nanyang Institute of Technology, Nanyang, Henan 473004, China \\ ${ }^{2}$ Guizhou Provincial Key Laboratory of Rock and Soil Mechanics and Engineering Safety, Guiyang 550025, China \\ ${ }^{3}$ School of Architecture and Civil Engineering, Chengdu University, Chengdu, Sichuan, China \\ ${ }^{4}$ Hami Tuoshi Conservancy and Hydropower Survey and Design Limited Liability Company, Hami, Xinjiang 839000, China \\ Correspondence should be addressed to Qi-Hong Wu; 15700679755@139.com
}

Received 8 December 2021; Revised 18 January 2022; Accepted 1 February 2022; Published 3 March 2022

Academic Editor: Yongfa Zhang

Copyright $\odot 2022$ Xin-Bao Gu et al. This is an open access article distributed under the Creative Commons Attribution License, which permits unrestricted use, distribution, and reproduction in any medium, provided the original work is properly cited.

\begin{abstract}
The original design scheme of ladder-shaped spillways in certain reservoirs is improved by using a hydraulic similar model experiment. The results of the original scheme demonstrate that the stilling basin cannot meet the requirement of safe discharge, and the flow state at the end of the stilling basin is violent and chaotic. The experimental method of the physical model was used to optimize the design of the spillway without changing the original plane layout. First, three steps in the ladder are added. The stilling basin is then replaced by the torsion plane. Finally, the longitudinal slope of the tail channel section is altered, and an experimental investigation on the flow state and energy dissipation rate is performed. The conclusions are drawn that the flow state of the water is obviously improved, and the energy dissipation rate increases; the optimal scheme produces the expected effects.
\end{abstract}

\section{Introduction}

To eliminate the residual energy of the water head crossing the dam or weir in a hydropower project [1], slip spillways or overflow dams are often applied to flip buckets for energy dissipation, and the stilling basins are constructed for the energy dissipation of the bottom flow [2]. However, to prevent the cavitation erosion damage, the shape of traditional spillways must be improved. With the development of the roller compacted concrete dam technique, the laddershaped spillways have been widely applied during the last 30 years $[3,4]$. They are characterized by good energy dissipation efficiency, low cost, and a small level of effort in construction $[5,6]$. For these reasons, the ladder-shaped spillways have been investigated by many researchers [7]. In particular, the design optimization of ladder-shaped spillways has become an important issue [8]. For example, the water movement in a ladder-shaped spillway can represent three types of flow states according to the unit width flow and the height and slope of the ladder, i.e., drop flow, slip flow, and transitional flow $[9,10]$. The occurrence of slip flow is regarded as the design criterion of ladder-shaped spillways. Drop flow often occurs under small flux conditions [11-13], and the transitional flow should be avoided. To date, a great number of experimental investigations on the energy dissipation characteristics of slip flow of the ladder-shaped spillways have been performed [14], but due to the complexity of water movement, unanimous conclusions have not been obtained $[10,15]$. In total, the optimization of water flow not only can shorten the time of construction but also can reduce the length of sting basin, so the optimization of flow state in the ladder-shaped spillway has great significance for the engineering design.

Essery [16] performed the experimental investigation on the hydraulic characteristics of ladder-shaped spillway during the 1970s, and the water flow is classified into Nappe flow and Skimming flow according to Essery's suggestion; the model similar experiment of ladder-shaped spillway is performed by Christodoulou [17] in 1993, and the results demonstrate that energy dissipating rate is related to the 
clinical depth of water and the height and number of ladders; the time-averaged pressure distribution law of ladder-shaped spillway under the conditions of different heights and gradients of ladder is investigated by Cui [18] in 2012 by using the hydraulic model experiment. Zhao et al. [19] performed the spillway experiment of the different sizes, and conclusions are drawn that the variation of ladder size has little influences on the time-average pressure along the way in 2017; and to consider the scale effect of hydraulic model, experimental investigation of using geotextile filter layer in articulated concrete block mattress revetment was performed by Yamini et al. [20] in 2017; to consider wave reflection effects for the future, experimental modeling about wave runup and rundown on ACB mats under granular and geotextile filters' condition is performed [21]; the discontinuous convex stepped spillway is suggested by Huang [22] in 2018, and the corresponding model experiment of hydraulic characteristics is investigated.

The above investigations improve the development of flow state optimization of ladder-shaped spillway, but some shortcomings still exist; for example, the influence of gradient in spillway has not been considered.

To improve the flow state of water in the spillway in the paper, a ladder-shaped spillway is proposed for optimization and redesign. Based on the relevant standards and requirements [23, 24], a hydraulic simulation model is established and the hydraulic characteristics of the optimized scheme are simulated under different cases $[25,26]$, resulting in a stable flow state of water in the optimized model and a good energy dissipation rate at the downstream chute [27, 28].

The paper is organized as follows: in Section 2, the engineering overview of the study area is introduced first. In Section 3, the experimental scheme, material, and methods are, respectively, stated. In Section 4, the resulting analysis of the original scheme is performed. In Section 5, the optimal investigation of the original scheme is introduced. In Section 6, the conclusions are drawn.

\section{Engineering Overview}

A certain reservoir is a multiyear project for regulation and control of water flow in a mountainous area. It is typified as small (1) size and with an engineering grade of IV. Its total length is $246 \mathrm{~m}$. The total reservoir capacity is $451 \times 10^{4} \mathrm{~m}^{3}$. Its dead water level is $1896.22 \mathrm{~m}$, the normal storage water level is $1927.88 \mathrm{~m}$, the design flood level is $1929.02 \mathrm{~m}$, and the collated flood level is $1930.01 \mathrm{~m}$. Water discharge under collated flood level conditions $Q_{\max }=122.3 \mathrm{~m}^{3} / \mathrm{s}$. Water discharge under design flood level conditions $Q_{\max }=46.27 \mathrm{~m}^{3} / \mathrm{s}$. A side-channel ladder-shaped spillway is located on the right bank of the reservoir. A WES practical weir was selected as the overflow weir. The initial regulating water level of the spillway is $1927.88 \mathrm{~m}$ and the crest elevation of the weir is the same as one of the initial regulating water levels. It is composed of a side weir section, regulation section, the stepped energy dissipation section of the discharge chute, and stilling basin section at the exit. The crest elevation of the overflow weir is $1928.38 \mathrm{~m}$, the bottom width at the head end of the side channel $b_{\mathrm{u}}$ is $3 \mathrm{~m}$, the bottom width at the end $b_{\mathrm{e}}$ is $6 \mathrm{~m}$, the length at the side-channel section is $20 \mathrm{~m}$, and the inner slope coefficient $\mathrm{m}=0.3$. The bottom slope at the side channel $i=0.004$, for which C25F300W8 steel is adopted. The regulation section is located at the pile number $0+020 \sim 0+035$. The length of the regulation section is $15 \mathrm{~m}$, the bottom slope is horizontal, and the cross-section form varies gradually from trapezoidal to rectangular. The elevation at the bottom plate is $1923.28 \mathrm{~m}$. The energy dissipation section of the ladder chute is next after the regulation section. Its length is $160 \mathrm{~m}$, its cross section is rectangular, its bottom width is $6 \mathrm{~m}$, and the step length of the ladder is $2 \mathrm{~m}$. The energy dissipation section for the bottom flow is next after it. Its total length is $31 \mathrm{~m}$, the depth of stilling basin is $1.0 \mathrm{~m}$, the bottom width is $6 \mathrm{~m}$, and the height of sidewall is $4.50 \mathrm{~m}$. The final section is known as the tail water section. Its cross-section form at the pile numbers $0+246 \sim 0+256$ is trapezoidal, the bottom width of the channel is $6 \mathrm{~m}$, and the length is $10 \mathrm{~m}$. The crosssection form at the pile number $0+256 \sim 0+303$ is trapezoidal, the bottom width of the channel is $6 \mathrm{~m}$, the length is $47 \mathrm{~m}$, and the slope coefficient is $1: 0.3$. The curved section is located in the place at the pile number $0+263.79 \sim$ $0+287.92$ with an angle of $46.07^{\circ}$ and a turning circle radius of $30 \mathrm{~m}$. A panoramic view of the spillway is shown in Figure 1.

Some problems exist in the engineering design: the flow state of water at the end of the stilling basin is excessive when the flow in the spillway reaches the magnitude of the design flood flux, jet flow is generated, and water leaps over the sidewall as the flow increases. The results demonstrate that the flow in the stilling basin cannot meet the safe discharge requirements. A distant hydraulic jump forms in the basin when the magnitude of the flow is greater than that of the 20year flood. Under the design flood level conditions, the water shot at the downstream of the channel, the spray splashed, and these results indicated that the original design of the stilling basin and tail water section was inadequate. The stones in a riprap pit are rolled up out of the pit by a 30-year flood flow and then are dashed into the downstream channel with possible damage to the sidewall. To improve the flow state of water in the spillway, sufficient energy dissipation of the upstream flow is accomplished, and the redesign and optimization of the original design of the spillway are necessary. The hydraulic models are established according to the correlative codes and specifications [29]. In addition, investigations are made of the hydraulic characteristics of the original scheme under different cases according to ratios similar to those of the hydraulic models and the results show good agreement.

\section{Hydraulic Modeling Experiment}

3.1. Testing Scheme. The scope of calculation for the model is given as follows: the total length of the spillway is $315 \mathrm{~m}$. The length of the side weir section is $20 \mathrm{~m}$, that of the regulating section is $15 \mathrm{~m}$, that of the ladder energy dissipation section is $190 \mathrm{~m}$, that of the stilling basin section is $21 \mathrm{~m}$, and that of the tail channel section is $69 \mathrm{~m}$. The similarity criterion of 


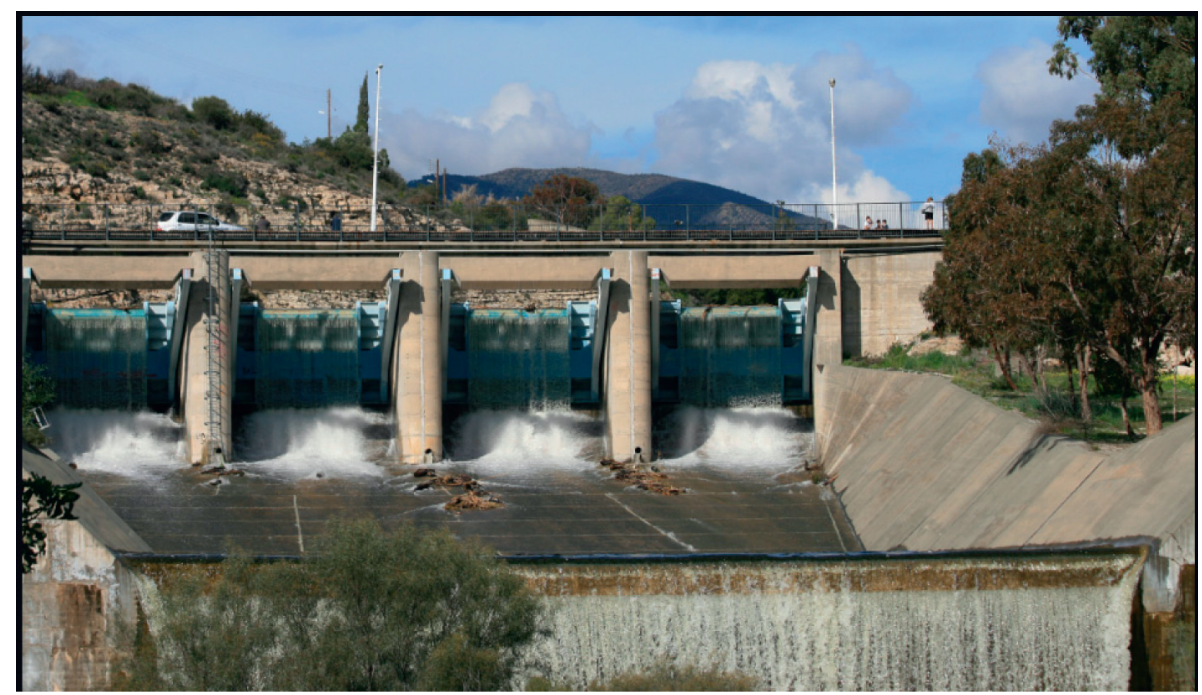

Figure 1: Panoramic view of ladder-shaped spillway.

gravity is followed according to the model design, and the normal model is adopted, the geometric scale of the model is $\lambda_{l}=25$, and the similarity scales of other hydraulic parameters are shown in Table 1. A plan view of the model is plotted in Figure 2; the full view of the model is shown in Figure 3; its research process is plotted in Figure 4.

3.2. Fabrication and Installation of Materials. The selection of experimental materials must approximate to the roughness of actual materials to reflect the flow regime of the water actually in the spillway. According to the principle of gravity similarity [30], this can be expressed as follows:

$$
\lambda_{n}=\frac{n_{p}}{n_{m}}=\lambda_{l}^{1 / 6}
$$

The roughness of the actual discharge structure is $n_{p}=0.015$, so the roughness of the experimental discharge structure can be calculated as $n_{m}=n_{p} / \lambda_{l}^{1 / 6}=0.015 / 25^{1 / 6}=0.0088$. The range of roughness of the plexiglass material is commonly within $0.007 \sim 0.009$, so the plexiglass is selected as the material of the spillway in the model.

The requirements of the experimental model are as follows: the layout of the planar conducting wire is determined by the shape and scope of the model. The bearings of the conducting wire are controlled by the theodolite, the permissive deviation is $\pm 0.1^{\circ}$, the elevation of the model is controlled by a level, and the experimental precision requirement should be satisfied [31, 32].

The experimental precision requirement is $\pm 0.3 \mathrm{~mm}$ for the permissible error of the elevation about the model structure and the permissible error between the cardinal point of the level and the zero point of the probe.

\subsection{Testing Method}

(1) Water supply facilities:
The water supply facilities in hydraulic experiments are composed of cistern, power pumps, level water towers, distributing and backwater tanks, etc.

(2) Experimental measuring instruments:

Measuring instruments of the water level and water surface line, including water level gauges and steel rules levels, were adopted to measure the water level at constant flow. A manometer was selected to monitor the pressure.

The flow velocity was measured using an LG-III-type multifunctional intelligent current meter with a pitot tube as the sensor.

A rectangular thin-walled weir was adopted to monitor the flux of constant flow. The type of gauging weir should meet the requirements of range and precision.

(3) The formula for calculating the rectangular thinwalled weir can be expressed as follows [33]:

$$
\begin{aligned}
Q= & m_{0} b \sqrt{2 g} H^{3 / 2}, \\
m_{0}= & \left(0.405+\frac{0.0027}{H}-0.03 \times \frac{B-b}{B}\right) \\
& \cdot\left[1+0.55\left(\frac{H}{H+P}\right)^{2}\left(\frac{b}{B}\right)^{2}\right],
\end{aligned}
$$

where $\mathrm{H}$ is the water head of weir, $m, \mathrm{P}$ is the height of weir, $m$, and $\mathrm{B}$ is the width of weir, $m$.

\section{The Results and Analysis of the Original Scheme}

The discharge capacity, water surface line, pressure, flow rate, and energy dissipation under five different conditions (including the collated flood level, design flood, 30-year 
TABLE 1: Hydraulic parameter similarity under the condition of gravity similarity.

\begin{tabular}{lccccc}
\hline Hydraulic parameters & Conversion relation & Similarity scale & Hydraulic parameters & Conversion relation & Similarity scale \\
\hline Length $l$ & $\lambda_{l}$ & 25 & Flow $Q$ & $\lambda_{Q}=\lambda_{l}^{5 / 2}$ & 3025 \\
Pressure $p$ & $\lambda_{p / \gamma}=\lambda_{l}$ & 20 & Time $t$ & $\lambda_{t}=\lambda_{l}^{1 / 2}$ & 5 \\
Flow velocity $v$ & $\lambda_{v}=\lambda_{l}^{1 / 2}$ & 5 & Roughness $n$ & $\lambda_{n}=\lambda_{l}^{1 / 6}$ & 1.60998 \\
\hline
\end{tabular}

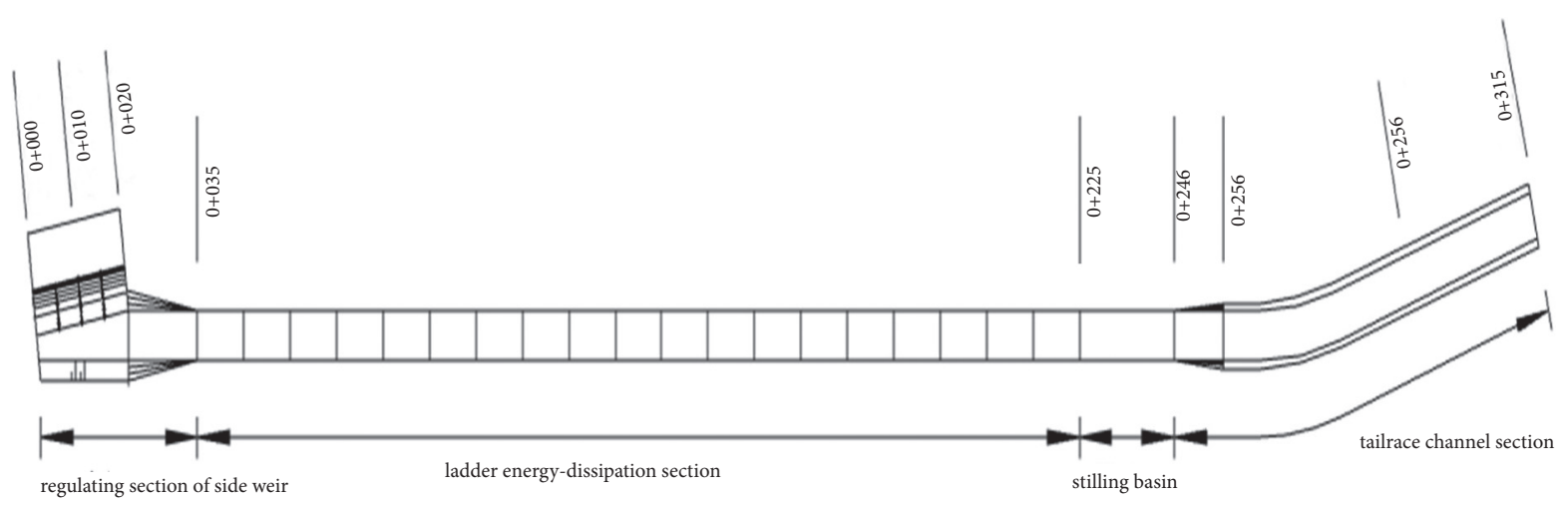

Figure 2: Plan view of the model.

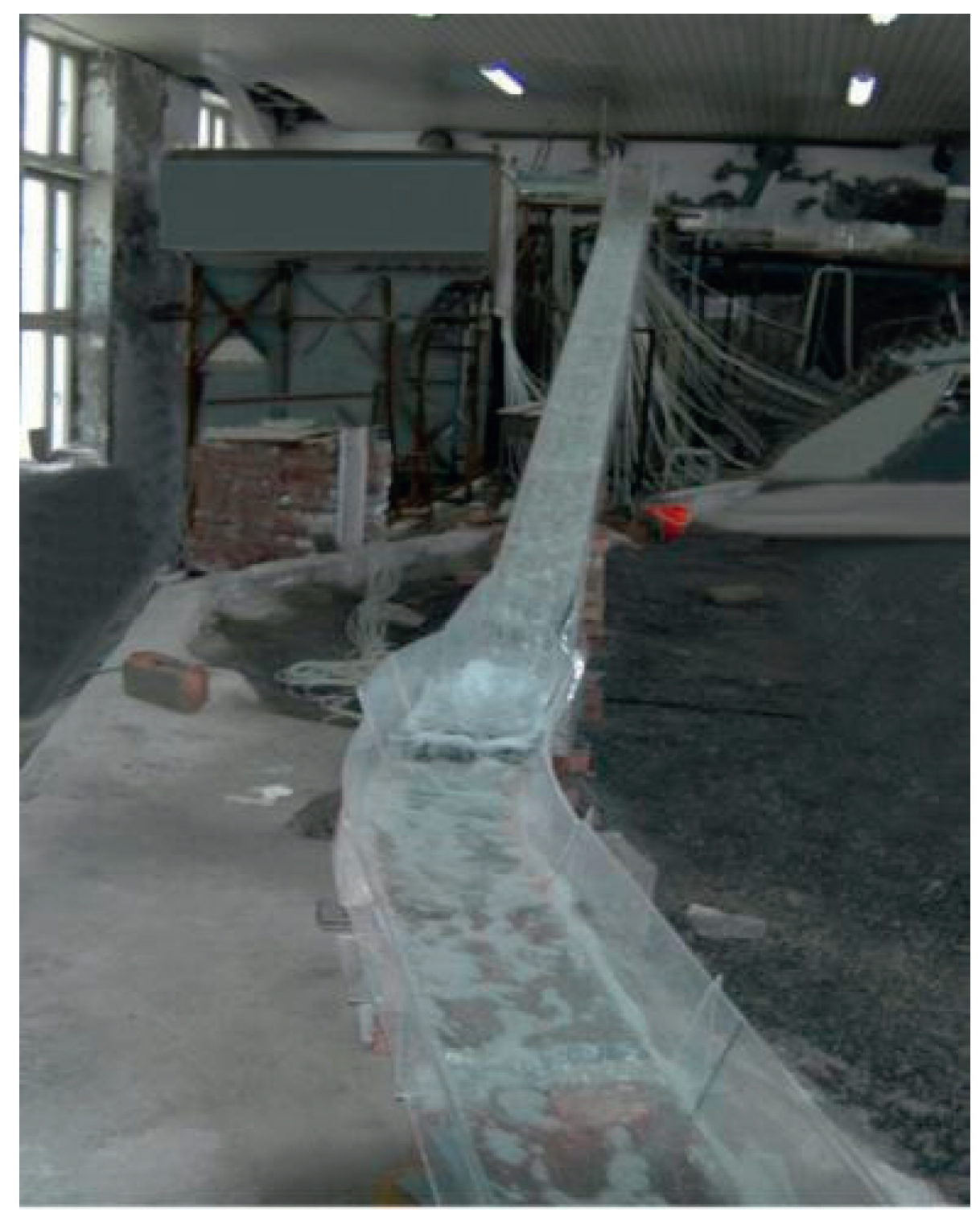

FIGURE 3: Full view of the model in the laboratory. 


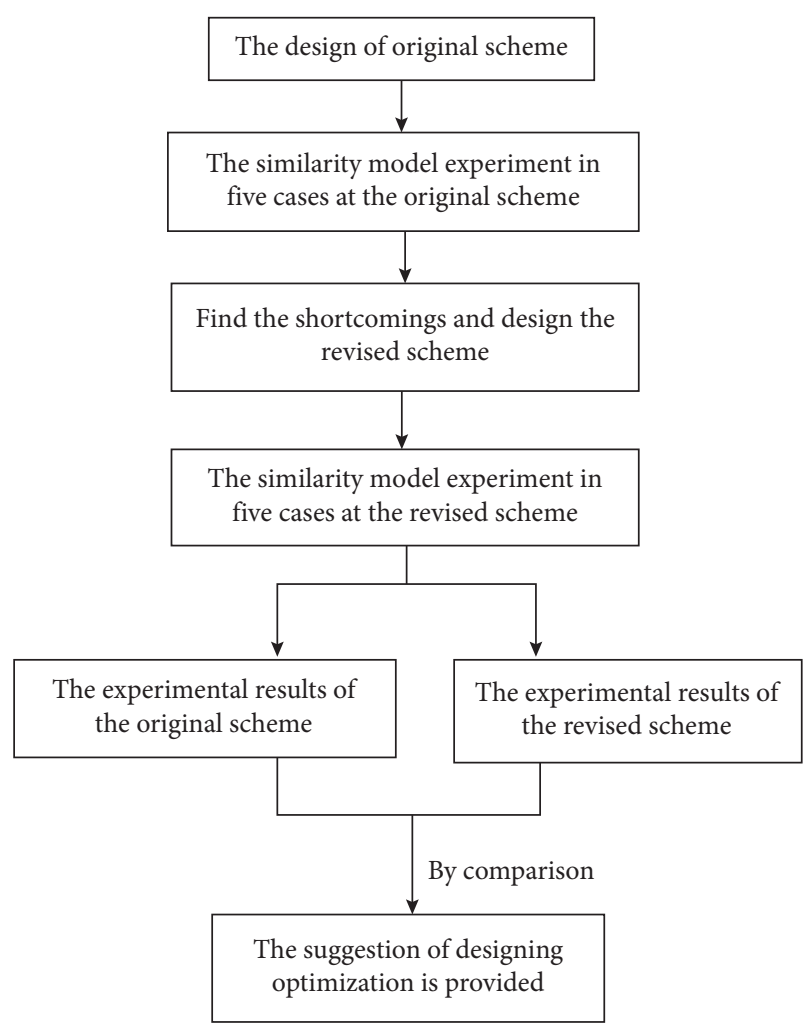

FIgURE 4: The flowchart of research process.

flood, 20-year flood, and 10-year flood) in the spillway are analyzed. To optimize the original design scheme, only the improved and optimal parts are introduced in this paper.

In experimentally determining the flow state of the ladder-shaped spillway, the flow state of water at the entrance to the stepped energy dissipation section of the discharge chute is stable at 5 different water levels. The hydraulic drop is formed at the 7 th ladder under a 10 -year flood, and the sliding water flow is stable on the surface of the ladders. Stable mass admixture cyclone rolls are formed at the recessed corner of each step, and the specific flow regime of the water is plotted in Figure 5(a). As the flow increases, the ladder location-generated aerifications are pushed downward; for example, aerifications occur at the 15th ladder under the design flood conditions. All of the flow states of water are aerated and rotary rolling water except for the collated flood level. These are shown in Figures 5(b)-5(d). Under collated flood conditions, the aeration and rolling of water decrease at the concave corner of the steps because the water depth increases. There exists a certain distance between the top of the rotary roll and the water surface, and its flow state is plotted in Figure 5(e).

When a 10-year flood occurs in the spillway, a submerged hydraulic jump is formed in the stilling basin; its flow state is plotted in Figure 6(a). When a 20-year or 30year flood occurs, the cross section ahead of the hydraulic jump moves downstream and a distant hydraulic jump is formed. These flow states are shown in Figures 6(b) and 6(c). As the flux increases, the cross section ahead of the hydraulic jump continues to move downstream. When the flow in the spillway reaches that of the design or collated flood, the hydraulic jump will move outside the basin, and no hydraulic jump will occur in the stilling pool. This flow state represents the rushing state. At this point, the baffle sills of the stilling pool are rushed straight, and the water forms a jet. The height of the jet exceeds that of one of the sidewalls, and the flow state of the water is plotted in Figures 6(d) and 6(e). The results demonstrate that the stilling pool in the original scheme cannot meet the requirement of safe discharge.

When the magnitude of discharge flow in the spillway reaches that of a 10-year flood, the water surface in the tail channel begins to fluctuate, and as the flow increases, the fluctuation becomes more violent, as plotted in Figures 7(a)$7(\mathrm{c})$.

To explain the results of the origin scheme quantitively, the flux of respective cross section is shown in Table 2, and it can be found in Table 2 that the magnitude of flux in the stilling basin and apron section is the biggest, and its maximum value is $12.37 \mathrm{~m} / \mathrm{s}$; the one in the side-channel section is the least, and its minimum value is $1.13 \mathrm{~m} / \mathrm{s}$; the results are consistent with the results of flow state, its flux distribution is irrational, and so the optimization of flow state at the original scheme is vital.

\section{The Optimal Investigation of the Original Scheme}

The following shortcomings exist according to the experimental results of the original scheme in the spillway:

(1) Large numbers of stable mixed cyclone rolls are generated at the recessed corner of each step in the ladder section of the spillway and this situation should be improved.

(2) The stilling pool cannot meet the requirement of safe discharge. A distant hydraulic jump is formed in the stilling pool when the magnitude of the flood exceeds the 20-year flood. Under the design flood conditions, the water shot at the downstream channel, the spray splash, and the flow regime are all unacceptable.

(3) The fluctuation of the water surface in the tailwater section is violent and the flow state is unstable.

5.1. The Optimal Design Scheme of the Spillway. Based on the experimental results of the original scheme, aimed at identifying the existing problems in the original scheme, some reference suggestions are provided. The improved suggestions are listed as follows:

(1) The planar steep slope should be made into a ladder, adding three-level ladders with a step length of $2.0 \mathrm{~m}$ and a height of $6.0 \mathrm{~m}$. In short, the steep slope section $(0+215-0+225)$ in the original stilling pool is omitted and is revised as three-level ladders. The pile number at the end of the ladder is $0+221$.

(2) The stilling pool in the original scheme is replaced with a pinch plane. Namely, the pinch plane is next 


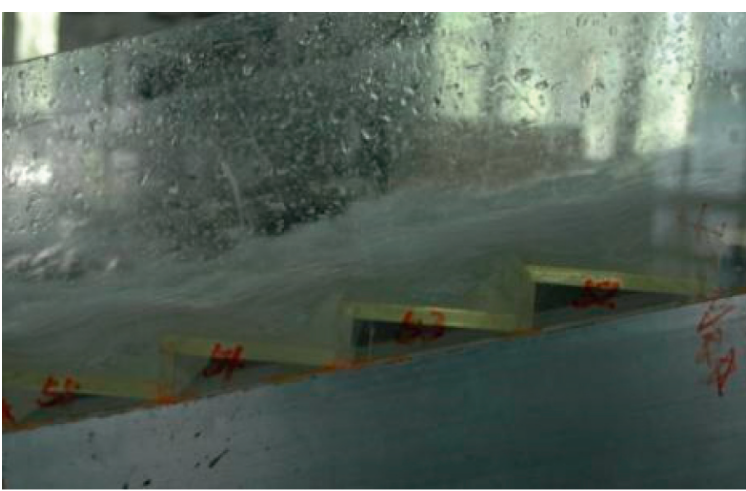

(a)

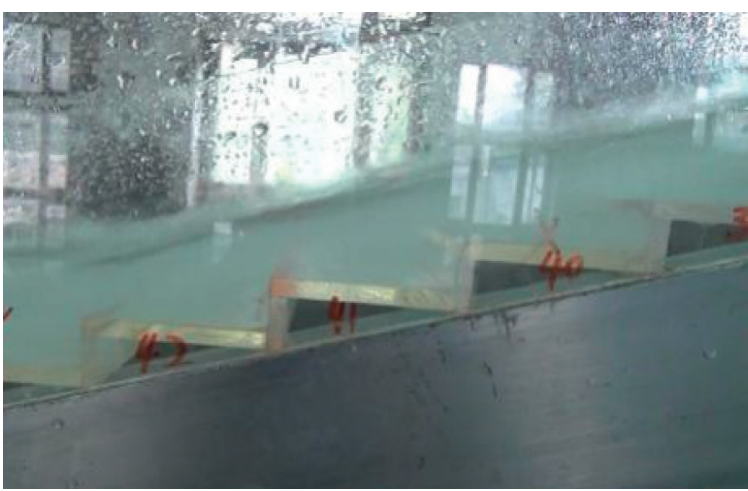

(c)

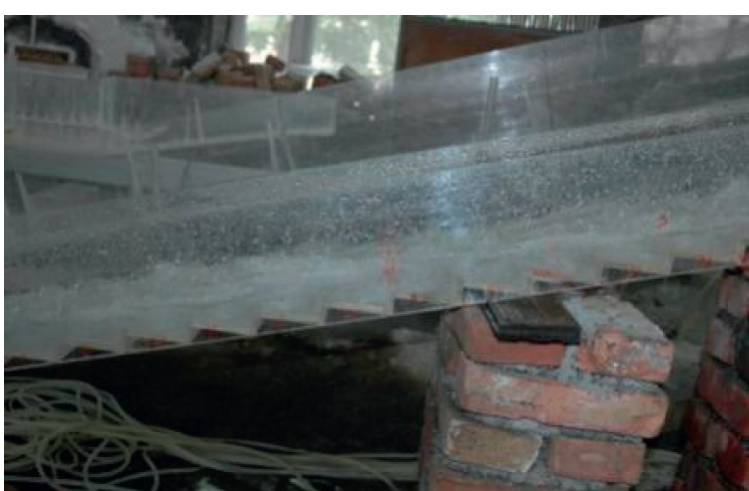

(b)

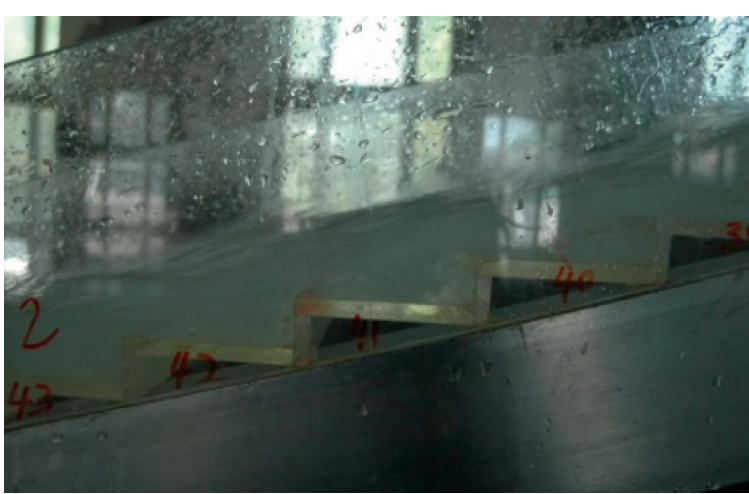

(d)

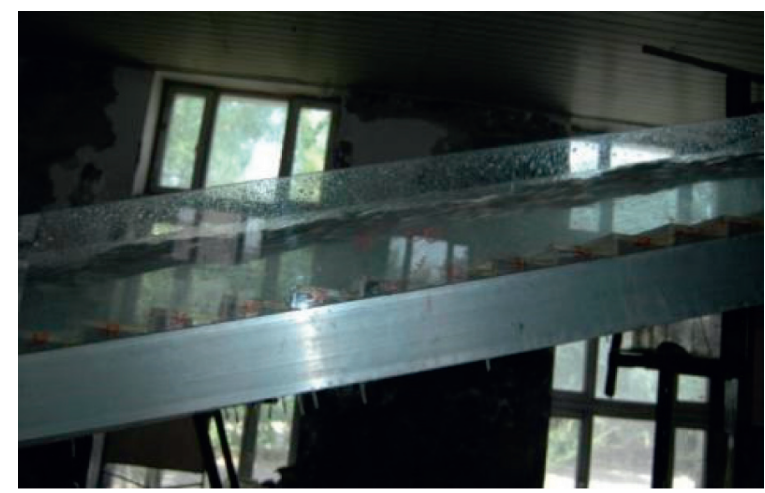

(e)

FIGURE 5: Flow state of water in the ladder section under different conditions. (a) Flow state under a 10-year flood. (b) Flow state under a 20year flood. (c) Flow state under a 30-year flood. (d) Flow state under the design flood condition. (e) Flow state under collated flood conditions.

to the end of the ladders and has a length of $30 \mathrm{~m}$, with the trapezoidal channel next to the pinch plane.

(3) The bottom width of the trapezoidal channel is $6 \mathrm{~m}$, and its length remains unchanged. The gradient of the original slope is revised to be $1: 1$ instead of 1 : 0.3 ; the longitudinal slope of the bottom plate in the channel is changed to $1: 50$ from the original $1: 100$, and the tail channel material is gravel and soil.
The specifics of the revised scheme are plotted in Figure 8.

5.2. The Optimal Results of the Original Design Scheme for the Spillway. Because the improvements in the optimal scheme are located at the end and downstream of the spillway, the flow state and relevant hydraulic parameters of water at the 


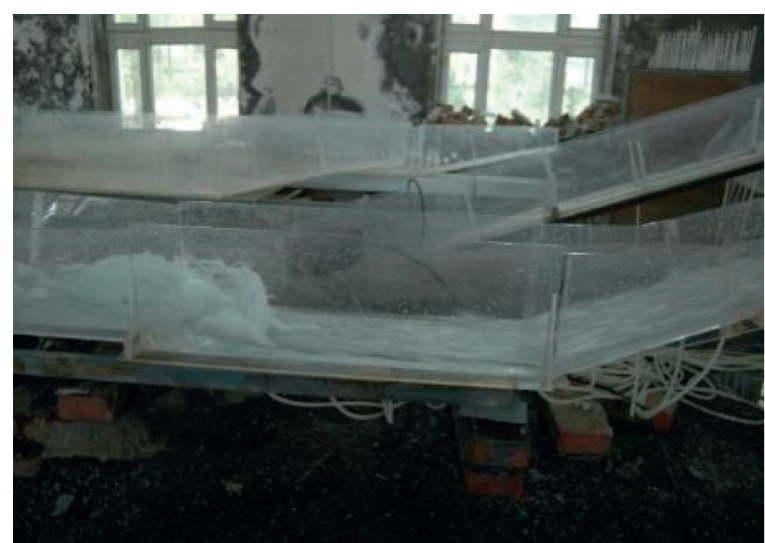

(a)

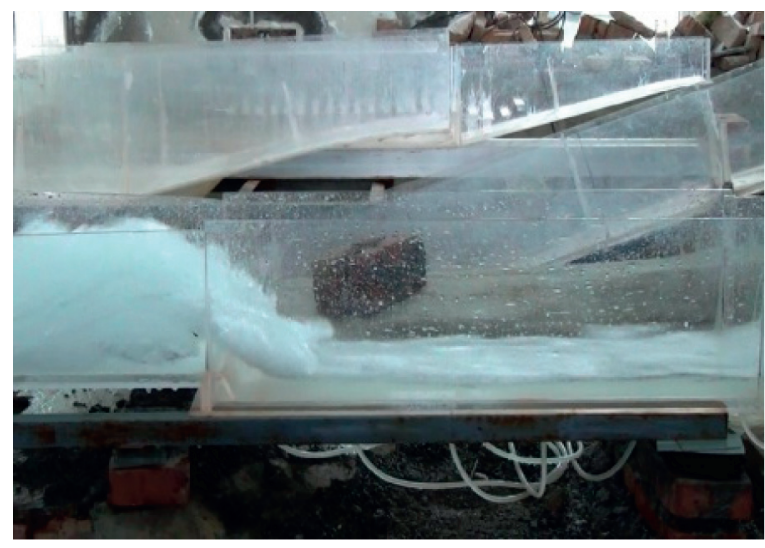

(c)

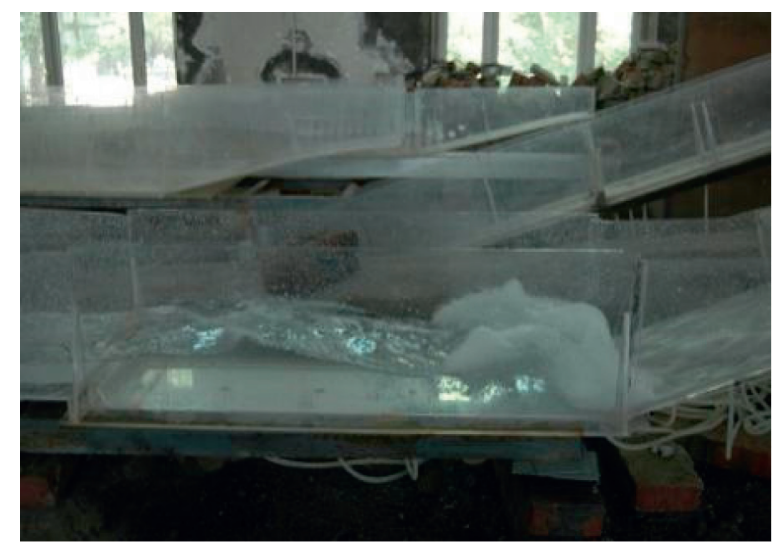

(b)

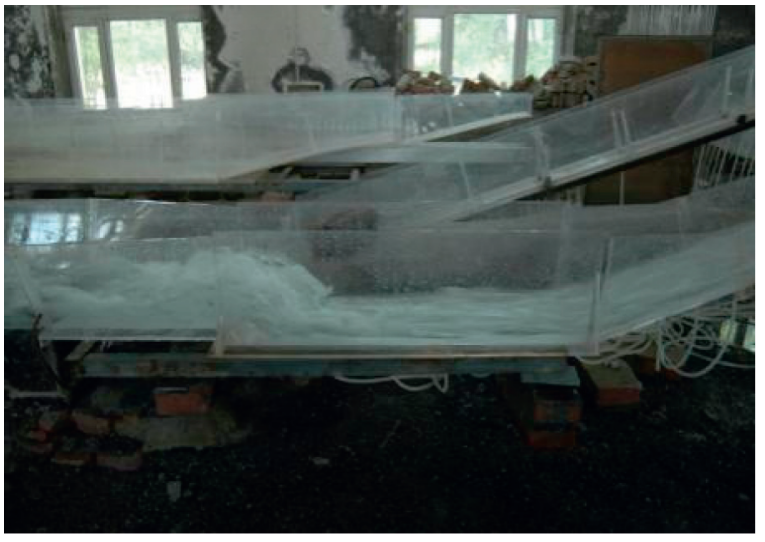

(d)

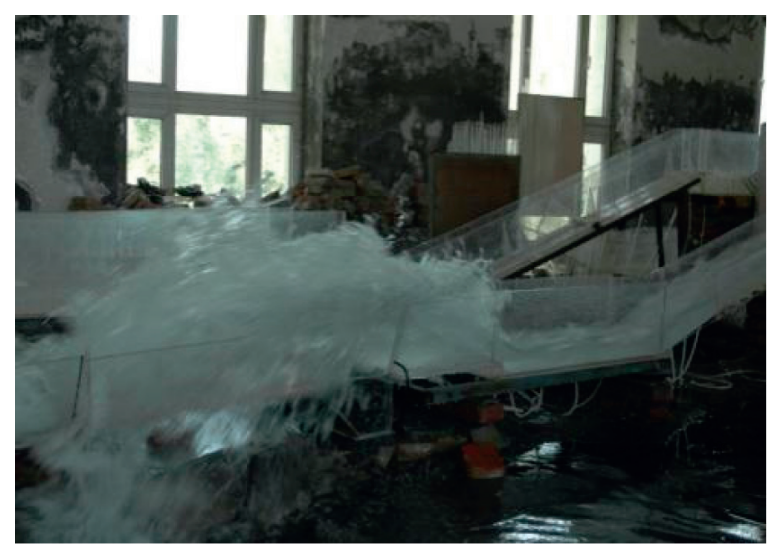

(e)

Figure 6: Flow state at the stilling pool section under different conditions. (a) Flow state under a 10-year flood. (b) Flow state under a 20-year flood. (c) Flow state under a 30-year flood. (d) Flow state under design flood condition. (e) Flow state under collated flood conditions.

side weir section, regulation section, and ladder section remain unchanged in the improved scheme. Only the improvements at the end of the spillway and the tailings channel section are implemented in the improved scheme.

The experimental results demonstrate that the drainage of water at the stepped energy dissipation section of the discharge chute can be aerified sufficiently when a 10-year flood is encountered in the spillway. The cream foams are represented on the surface of the entrance and tail channel section. The fluctuation in the water surface is slight, and its flow state is shown in Figure 9(a). The swell represents the surface of the entrance section when a 20-year flood is encountered in the spillway. The cream foam bestrews the whole surface at the tailings channel section, as shown in Figure 9(b). The flow state of the water at the bend section of the tail channel represents the classical curve flow pattern; namely, the water depth in the concave bank is deeper than that in the convex bank, so a transverse water slope is 


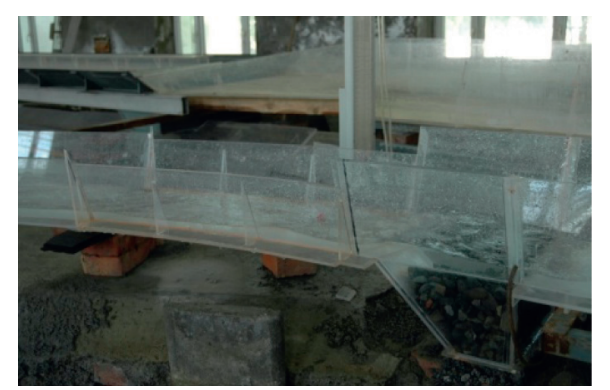

(a)

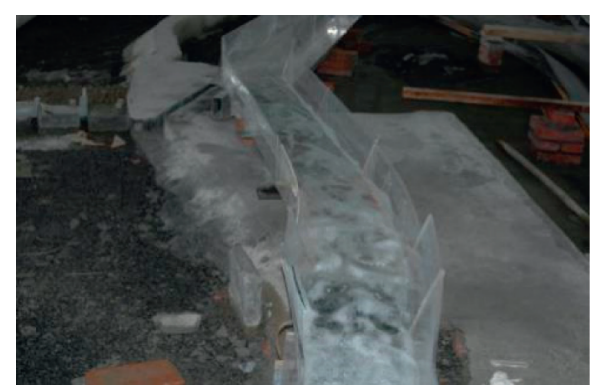

(b)

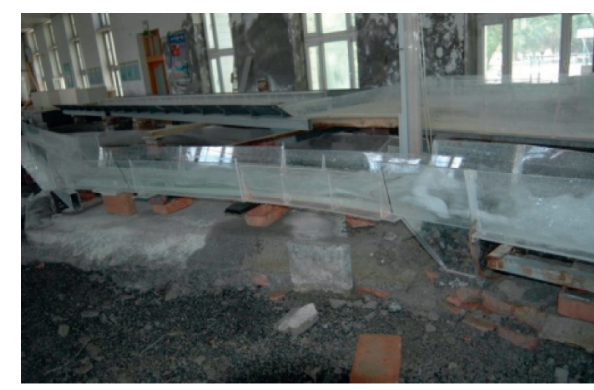

(c)

FiguRe 7: Flow state in the spillway under different conditions. (a) Flow state under a 10-year flood. (b) Flow state under a 20 -year flood. (c) Flow state under a 30-year flood.

TABLE 2: The average flux of classical cross section in the spillway.

\begin{tabular}{|c|c|c|c|c|c|c|c|c|c|c|}
\hline \multirow{4}{*}{$\begin{array}{l}\text { Pile number } \\
\text { The flux }(\mathrm{m} / \mathrm{s})\end{array}$} & \multicolumn{2}{|c|}{ Side-channel section } & \multicolumn{3}{|c|}{ Side channel section } & \multicolumn{2}{|c|}{ Regulation section } & \multicolumn{3}{|c|}{ Chute section } \\
\hline & Weir front $7 \mathrm{~m}$ & Weir top & $0+000$ & $0+007.5$ & $0+015$ & The front & The end & $0+055$ & $0+105$ & $0+125$ \\
\hline & 1.13 & 5.32 & 2.10 & 2.66 & 3.92 & 3.92 & 5.11 & 9.73 & 10.13 & 10.53 \\
\hline & \multicolumn{5}{|c|}{ Chute section (ladder) } & \multicolumn{5}{|c|}{ Stilling basin and apron section } \\
\hline Pile number & $0+155$ & $0+185$ & $0+205$ & $0+220$ & $0+225$ & The entrance & In the basin & Apron & & \\
\hline The flux $(\mathrm{m} / \mathrm{s})$ & 10.43 & 10.97 & 10.62 & 12.57 & 11.87 & 11.87 & 12.37 & 7.37 & & \\
\hline
\end{tabular}

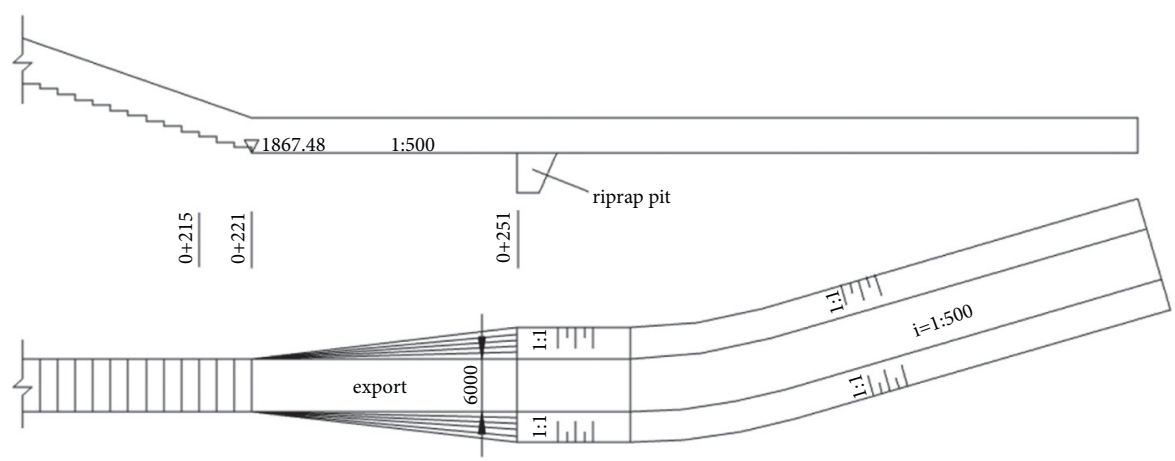

FIGURE 8: Schematic diagram of the improved scheme.

formed, and the shock wave is formed from the end of the bend to the downstream channel, and downstream channel is damaged, so it is suggested that the riprap pit should be canceled in the revised scheme. And as the flux increases, the height difference of the water surface between the concave and convex banks at the bend section increases. This means that the lateral gradient of the water surface increases and the intersection angle between the shot wave and the axis line of the channel decreases, so the flow state of the water is obviously improved. The flow state of water under this condition is plotted in Figures 9(b)-9(d). The rocks in a riprap pit begin to roll and rush downstream when a 30-year flood occurs. The height of the water can exceed that of the outside of the sidewall at the end of the bend section when a collated flood is discharged into the spillway, which means that the height of the sidewall in the bend section is inadequate, so it is suggested that the height of side wall in concave bank of bends should be increased. 


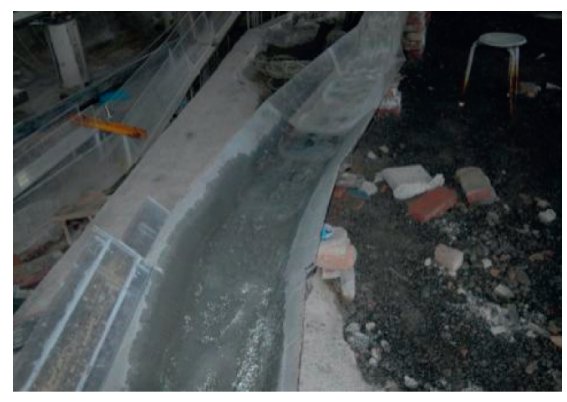

(a)

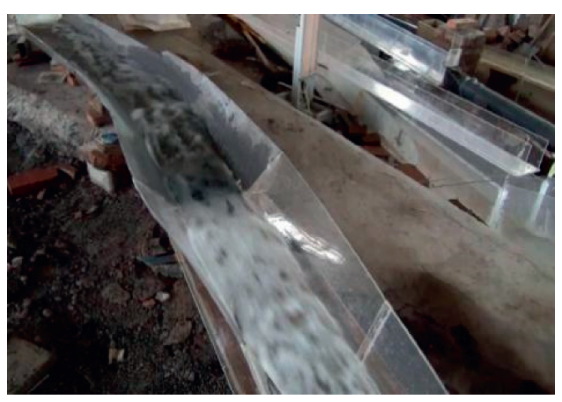

(b)

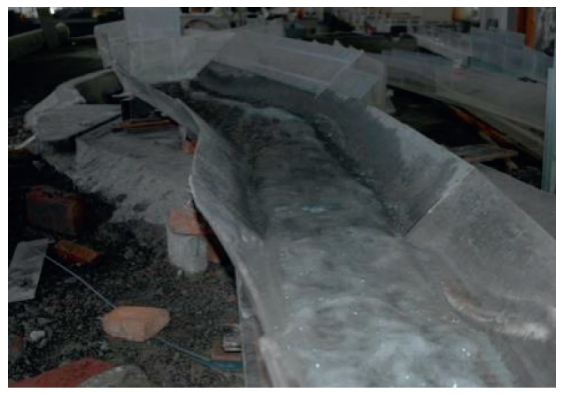

(d)

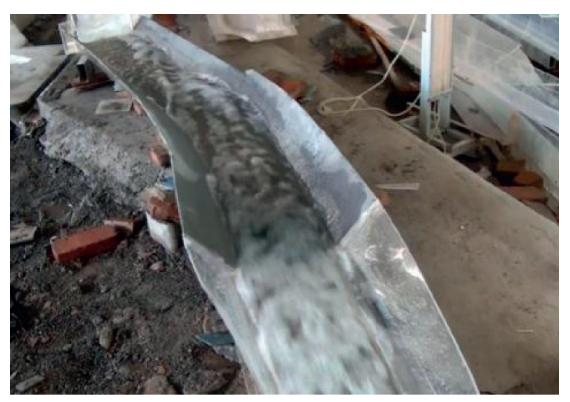

(c)

Figure 9: Flow regime at the tail channel section under different conditions in the improved scheme. (a) Flow state under a 10-year flood. (b) Flow state under a 20-year flood. (c) Flow state under a 30-year flood. (d) Flow state under design flood conditions.

TABLE 3: Energy dissipation rate of the spillway.

\begin{tabular}{lccc}
\hline Conditions & Water level & $\begin{array}{c}\text { Energy dissipation rate } \\
\text { Original } \\
\text { scheme }\end{array}$ & $\begin{array}{c}\text { Revised } \\
\text { scheme }\end{array}$ \\
\hline Design conditions & $1929.02 \mathrm{~m}$ & 83.26 & 88.05 \\
Collated conditions & $1930.01 \mathrm{~m}$ & 75.32 & 79.54 \\
\hline
\end{tabular}

5.3. Energy Dissipation Analysis of the Spillway in the Improved Scheme. For ladder-shaped spillways under slip flow conditions, the energy dissipation of water is fulfilled by the exchange between the split and aeration of the water and the turbulent motion of whirlpools, both in the mainstream and bottom. The energy dissipating efficiency at the ladder section can be measured by using the energy dissipation rate. The energy dissipation rate is defined as the ratio between the energy that is consumed from the top of the weir to the end ladder and the total energy. The formula for energy dissipation rate can be expressed as follows:

$$
\eta=\frac{E_{1}-E_{2}}{E_{1}},
$$

where $\eta$ is the energy dissipation rate, $E_{1}$ is the initial energy of water, and $E_{2}$ is the energy at the entrance cross section of the stilling basin. To compare with the two different cases, the energy dissipation rate of the ladder-shaped spillway is shown in Table 3.

Table 3 shows that the energy dissipation rate under the design flood conditions increases from $83.26 \%$ to $88.05 \%$ at the revised scheme, an increase of $4.79 \%$. Under collated flood flood conditions, the energy dissipation rate increases from $75.32 \%$ to $79.54 \%$, an increase of $4.22 \%$. These results demonstrate that the efficiency obtained in the improved scheme has attained the expected result, and the flow state of water is improved.

\section{Conclusions}

Based on the original experiment of the engineering of a given spillway in an arid area, it can be found that the distribution of the flow state about water at the entrance section is extremely uneven, and there still exists the phenomena of water wings at the downstream ladders and many aerification rolls. To improve the flow state of water in the spillway, a series of experimental investigations focused on the optimal structural form of the spillway have been performed, and conclusions are drawn as follows:

(1) Based on the improved design scheme, aerification of the drainage of water at the stepped energy dissipation section of the discharge chute is sufficient under the various different cases. A cream foam is found on the surface of the entrance and tail channel section. The fluctuation in the water surface is slight and the flow state of the water at the bend section of the tail channel represents the classical curve flow pattern; namely, the water depth in the concave bank is deeper than that in the convex bank, so a transverse water slope is formed, and the shock wave is formed from the end of the bend to the downstream channel. The lateral gradient of the water surface increases, the intersection angle between the shot wave and the axis line of the channel decreases, and the flow state of the water is obviously improved. 
(2) In comparison with the energy dissipation rate between the designed and collated floods, conclusions can be drawn that the energy dissipation rate under design flood conditions increases to $88.05 \%$ from $83.26 \%$ in the revised scheme, which is an increase of $4.79 \%$. Under collated flood conditions, the energy dissipation rate is enhanced to $79.54 \%$ from $75.32 \%$ and increases by $4.22 \%$, which demonstrates that the expected target is achieved in the improved design scheme, and the flow state of water is obviously improved.

(3) The pebbles in the riprap pit are rolled by the water flow when a 30-year flood occurs and rush into the downstream, and downstream channel is damaged, so it is suggested that the riprap pit should be canceled.

(4) Under collated flood conditions, the water flow turns over at the side wall in the concave bank, so it is suggested that the height of side wall in concave bank of bends should be increased.

\section{Data Availability}

The data used to support the findings of this study are available from the corresponding author upon request.

\section{Conflicts of Interest}

The authors declare that they have no conflicts of interest.

\section{Acknowledgments}

This work was supported by a cooperative project at the Nanyang Institute of Technology (520009), the National Natural Science Foundation in China (41672357), and the Doctoral Startup Foundation (510126). The authors also thank the Sichuan Science and Technology Program (no. 2020YJ0424) and the Regional Innovation Cooperation Programs of Sichuan Province (2021YFQ0050) for their support.

\section{References}

[1] N. Yue, D. Zhang, J. Chen et al., "The development and validation of the inter-wrapper flow model in sodium-cooled fast reactors," Progress in Nuclear Energy, vol. 108, pp. 54-65, 2018.

[2] H. Kamide, Y. Sakamoto, and S. Kubo, "Progress of design and related researches of sodium-cooled fast reactor in Japan," in Proceedings of the International Conference on Fast Reactors and Related Fuel Cycles: Next Generation Nuclear Systems for Sustainable Development (FR17), Yekaterinburg, Russian, 2017.

[3] A. Khoshkonesh, B. Nsom, and S. Gohari, "A comprehensive study on dam-break flow over dry and wet beds," Ocean Engineering, vol. 188, 2019.

[4] M. La Rocca, C. Adduce, A. B. Sciortino, and A. B. Pinzon, "Experimental and numerical simulation of three-dimensional gravity currents on smooth and rough bottom," Physics of Fluids, vol. 20, no. 10, Article ID 106603, 2008.
[5] Y. Yasuda, "Characteristics of plunging flows in stepped channel chutes," in Proceedings of the International Workshop on State-of-the-Art Hydraulic Engineering, Bari, Italy, June 2004.

[6] M. Bieri, R. M. Fede, and J. L. Boillat, "Energy dissipation downtream of pinao key weirs-case study of gloriettes dam," in Proceedings of the Labyrinth and Piano Key Weirs, CRC/ Balkema, p. 123, Leiden, Netherlands, 2011.

[7] X. B. Gu, Q. H. Wu, and Y. H. Zhu, "The experimental investigation on the propagation process of crack for brittle rock similar material," Geotechnical and Geological Engineering, vol. 37, no. 6, pp. 4731-4740, 2019.

[8] F. Renna, U. Fratino, and J. Matos, "Air-water flow fea-tures in skimming flow over steeply sloping stepped spill-ways," in Proceedings of the XXXI IAHR Congress, Seoul, South Korea, 2005.

[9] H. Shahheydari and J. N. R. Barati, "Discharge coefficient and energy dissipation over stepped spillway under skimming flow regime," KSCE Journal of Civil Engineering, vol. 19, no. 4, 2015.

[10] M. M. Tabari and S. Tavakoli, "Effects of stepped spillway geometry on flow pattern and energy dissipation," Arabian Journal for Science and Engineering, vol. 41, no. 4, pp. 1215-1224, 2016.

[11] O. A. Yamini, M. R. Kavianpour, and A. Movahedi, "Performance of hydrodynamics flow on flip buckets spillway for flood control in Large dam reservoirs," Journal of Human, Earth, and Future, vol. 1, no. 1, pp. 39-47, 2020.

[12] N. J. H. Al-Mansori, T. J. M. Alfatlawi, K. S. Hashim, and L. S. Al-Zubaidi, "The effects of different shaped baffle blocks on the energy dissipation," Civil Engineering Journal, vol. 6, no. 5, pp. 961-973, 2020.

[13] S. M. Mousavimehr, O. A. Yamini, and M. R. Kavianpour, "Performance assessment of shockwaves of chute spillways in Large dams," Shock and Vibration, vol. 2021, 17 pages, 2021.

[14] X.-P. Zhou, X.-B. Gu, M.-H. Yu, and Q.-H. Qian, "Seismic bearing capacity of shallow foundations resting on rock masses subjected to seismic loads," KSCE Journal of Civil Engineering, vol. 20, no. 1, pp. 216-228, 2016.

[15] H. Shahheydari, E. J. Nodoshan, and R. Barati, "Discharge coefficient and energy dissipation over stepped spillway under skimming flow regime," Journal of European Economy, vol. 19, no. 4, pp. 174-181, 2015.

[16] H. Essery, "The hydraulic design of stepped spillway," 1971.

[17] C. George, "Energy dissipation on stepped spillways," Journal of Hydraulic Engineering, vol. 119, no. 5, 1993.

[18] R. Cui, "The Hydraulic Characteristics of the Flow In Stepped Spillway with Slopes," Xinjiang Agriculture University, Urumqi, China, 2012.

[19] X. H. Zhao, Study on Hydraulic Characteristics of Stepped Spillways with Different Sizes, Qinghai University, Xining, China, 2014.

[20] O. Aminoroayaie Yamini, S. H. Mousavi, and M. R. Kavianpour, "Experimental investigation of using geotextile filter layer in articulated concrete block mattress revetment on coastal embankment," Journal of Ocean Engineering and Marine Energy, vol. 5, no. 2, pp. 119-133, 2019.

[21] O. A. Yamini, M. R. Kavianpour, and S. H. Mousavi, "Wave run-up and rundown on ACB Mats under granular and geotextile filters' condition," Marine Georesources and Geotechnology, vol. 10, pp. 1-12, 2017.

[22] Z. M. Huang, B. Fu, and Y. Chen, "Aeration and hydrodynamic pressure characteristics for outer convex step in steep slope section," Journal of Water Resources \& Water Engineering, vol. 29, no. 3, pp. 138-143, 2018, In Chinese. 
[23] J. H. W. U, B. Zhang and F. Ma, "Inception point of air entrainment over stepped spillways," Journal of Hydro Dynamics, vol. 25, no. 1, pp. 91-96, 2013.

[24] M. T. Ohtsu, "Aerated flow characteristics of skimming flow over stepped chutes," Journal of Hydraulic Research, vol. 50, no. 4, pp. 427-434, 2012.

[25] Y. Zhao, C. L. Wang, L. Ning, H. F. Zhao, and J. Bi, "Pore and fracture development in coal under stress conditions based on nuclear magnetic resonance and fractal theory," Fuel, vol. 309, Article ID 122112, 2022.

[26] Y. Zhao, C. L. Wang, and J. Bi, "Analysis of fractured rock permeability evolution under unloading conditions by the model of elastoplastic contact between rough surfaces," Rock Mechanics and Rock Engineering, vol. 53, no. 12, pp. 5795-5808, 2020.

[27] Y. Zhao, C. Wang, M. Teng, and J. Bi, "Observation on microstructure and shear behavior of mortar due to thermal shock," Cement and Concrete Composites, vol. 121, Article ID 104106, 2021.

[28] Y. Zhao, Y. Zhang, H. Yang, Q. Liu, and G. Tian, "Experimental study on relationship between fracture propagation and pumping parameters under constant pressure injection conditions," Fuel, vol. 307, Article ID 121789, 2022.

[29] J. Bi, P. F. Liu, and F. Gan, "Effects of the cooling treatment on the dynamic behavior of ordinary concrete exposed to high temperatures," Construction and Building Materials, vol. 248, Article ID 118688, 2020.

[30] Y. Zhao, J. Bi, C. Wang, and P. Liu, "Effect of unloading rate on the mechanical behavior and fracture characteristics of sandstones under complex triaxial stress conditions," Rock Mechanics and Rock Engineering, vol. 54, no. 9, pp. 4851-4866, 2021.

[31] X.-B. Gu and Q.-H. Wu, "Seismic stability analysis of waterfront rock slopes using the modified pseudo-dynamic method," Geotechnical and Geological Engineering, vol. 37, no. 3, pp. 1743-1753, 2018.

[32] N. Yue, D. L. Zhang, and J. Chen, "The development and validation of the inter-wrapper flow model in sodium-cooled fast reactors," Progress in Nuclear Energy, vol. 108, pp. 54-65, 2018.

[33] I. Ohtsu, Y. Yasuda, and M. Takahashi, "Flow characteristics of skimming flows in stepped channels," Journal of Hydraulic Engineering, vol. 130, no. 9, pp. 860-869, 2004. 